\title{
THE BASAL SEGMENTS OF THE HEXAPOD LEG.
}

\section{B. WALTON.}

Ar the base of each leg in the Hexapoda are a series of segments and sclerites which enter into the composition and serve as a support of the appendage. These are the trochanter, coxa genuina, meron ${ }^{1}$ trochantin, and antecoxal piece. The difficulties in the way of accounting for the origin of these segments and homologizing them in the various orders have caused morphologists more or less trouble.

By reason of the fusion which has taken place between the trochanter and femur in the Myriopoda and Hexapoda, many writers on insect anatomy hold that the trochanter is merely a portion of the femur which has in some manner become constricted so as to form an apparent but not an actual segment. The fusion, however, between the two parts is a specialization acquired during the later embryonic stages of development. ${ }^{2}$ A similar case of ankylosis is often noticeable between certain segments of the appendages in Crustacea. Bordage ${ }^{3}$ has advanced the theory, from observations based on certain Phasmidæ, that the two segments have become coalesced in the Arthropoda as a result of ecdysis. Since the same fusion, however, is very pronounced in the Myriopoda, particularly among the Diplopoda, where Verhoeff ${ }^{4}$ believes the trochanter

${ }^{1}$ In order to distinguish between these two parts, which have been confused under the name "coxa," I have called the piece articulating with the trochanter coxa genuina, and the posterior lateral part articulating with the epimeron, meron (from $\mu \eta \rho \delta s=$ thigh), since its lateral margin is always found in articulation with the epimeron.

2 The "two-jointed trochanter" of Hymenoptera [Terebrantia] appears to be a secondary modification, the lower part ["apophysis," Ratzeburg] being derived from the femur. This is the view held by Sharp, Camb. Nat. Hist., vol. v, p. 520.

${ }^{3}$ On the Probable Mode of Formation of the Fusion between the Femur and Trochanter in Arthropoda. Comptes Rendus de la Société de Biologie, tome v, No. 28, pp. 839-842, 1898. Also Ann. and Mag. Nat. Hist., vol. iii, pp. 159-162, 1899.

4 Ein Beitrag zur Kenntniss der Glomeriden. I895. 
is in many cases entirely absent, it is evident that it is a characteristic of a primitive stem form, and has not arisen, as Bordage suggests, from an "ancestral form belonging to the existing Phasmids in which there was a distinct articulation between the two consecutive segments." 1 In addition to ecdysis, insisted upon by Bordage, ${ }^{2}$ we must take into consideration various other selective factors, chief among which appear to have been mutilations by enemies. The severing of the segments, which resulted from either factor, would prob-

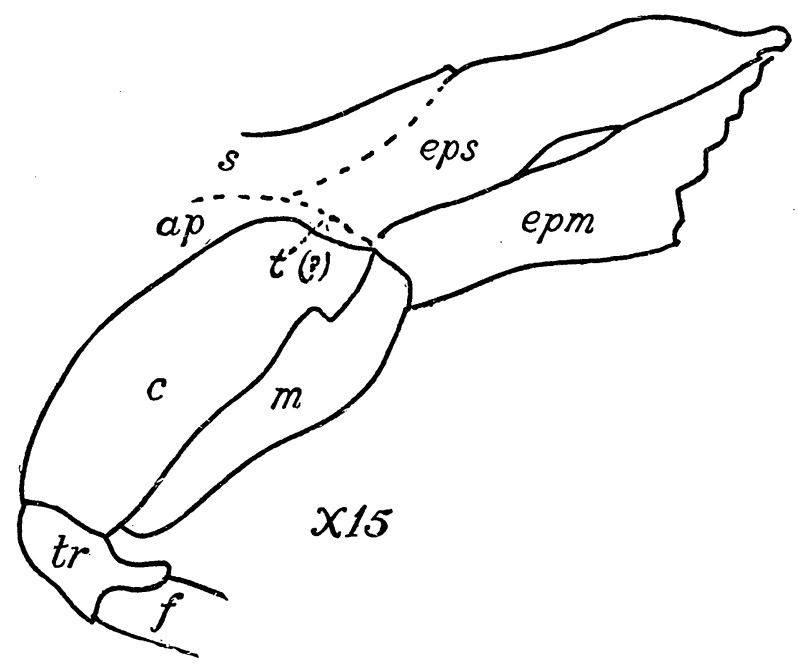

FIG. x. - Panorpa communis. Metathorax; $c$, coxa genuina; $m$, meron; eps, episternum; epm, epimeron; $a p$, antecoxal piece; $s$, sternum; $t$ (?), trochantin; $t r$, trochanter $f$, femur.

ably occur near the base of the appendage, and the favored forms would be those in which the two segments were approaching the fused condition, the invagination of the chitinous wall preventing undue hemorrhage. Autotomy, which Bordage so fully explains, would undoubtedly play an important part here. It also appears advantageous to poly-

1 I have adopted the translation as given by Austen.

2 The position of Bordage in regard to the manner in which the fusion has come about is clearly on the side of Neo-Lamarckianism, since he attributes it to " a mechanical strain," and says that it is an "example of a character acquired by use ... and then transmitted by heredity." This conclusion, however, as I have endeavored to show, seems unwarranted. 
podial forms that a series of the appendages move more or less in unison, and it is obvious that such rhythmic motion is better maintained with the articulation of a coxa and trochanter alone than with an additional articulation between the trochanter and femur. This may be a factor in accounting for the more pronounced fusion of the two segments in the Diplopoda.

In 1893 Hansen $^{1}$ endeavored to homologize the trochanter of the Hexapoda with the ischiopodite in Crustacea. This homology was based on the supposition that the part assumed by him to be the trochantin ${ }^{2}$ in the Cicadaria (Cicadidæ, Ful-

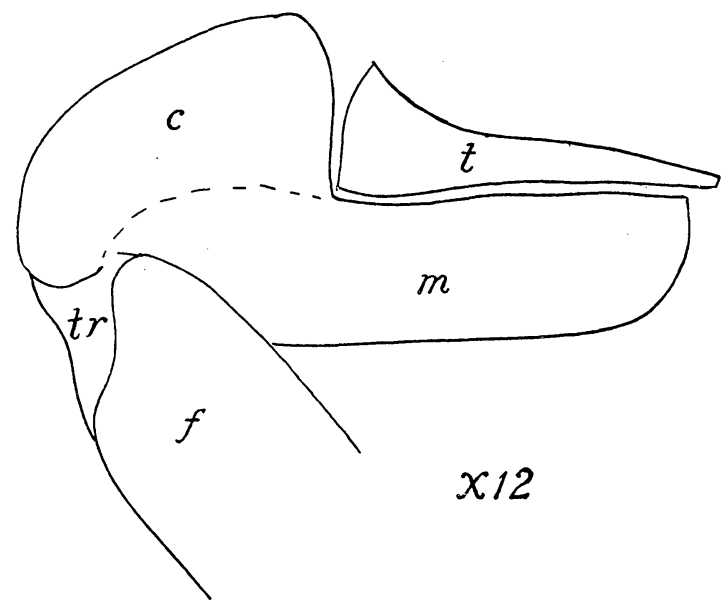

FIG. 2. - Hydrophilus triangularis. Mesothoracic coxa.

goridæ, Cixidæ, etc.) was the homologue of the coxopodite in Crustacea. In referring to Machilis, he has considered the trochantin of the prothoracic coxa as a primary segment, homologous with the coxopodite. From comparisons, however, with both Chilopoda and Diplopoda, we would regard the trochantin rather as a specialized character of the Hexapoda, which is absent in the Crustacea. Homologies based upon the form of the segment and manner of articulation certainly appear ques-

${ }^{1}$ Zur Morphologie der Gliedmassen und Mundtheile bei Crustaceen und Insecten. Zool. Anz., pp. 193-198, 201-21 2, 1893.

2 It seems probable that Hansen has here applied the name "trochantin" to the antecoxal piece and trochantin together. 
tionable, since pronounced variations often occur within the limits of a single group. ${ }^{1}$

Until a closer relationship can be shown in the lines of descent of the two groups, Hexapoda and Crustacea, it would seem that an attempt to homologize the segments of the

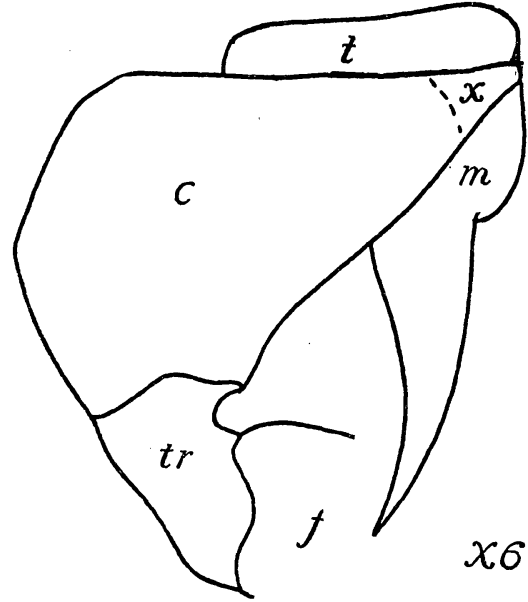

FIG. 3. - Pomponia imperatoria. Metathoracic coxa ; $x$, area formed by development of coxal groove [Fig. $4 c^{\prime}$ ] and corresponding to lateral portion of $c$, Fig. 4 . appendages would scarcely be justified. For the time being, we must assume that the segmentation of an appendage is a result brought about by certain indefinite factors, and that in these groups it does not necessarily imply a phylogenetic relationship.

That the trochanter of the Myriopoda and Hexapoda represents a distinct segment seems obvious, and that its fusion with the femur took place in some ancestral myriopod-like form appears probable.

Three sclerites, as a rule, enter into the composition of the segment to which the name coxa is given, viz., coxa genuina, meron, and trochantin. Audouin ${ }^{2}$ applied the name "trochantin" 3 to the lateral margin of the posterior coxa (meron) in Dytiscus circumflexus, erroneously believing it homologous with the trochantin on the anterior and mesal coxæ ${ }^{4}$ of Buprestis

1 Compare Arachnida, or, in Coleoptera, the metathoracic coxa of Dytiscus and Hydrophilus.

2 Recherches anatomiques sur le thorax des animaux articules et celui des insectes hexapodes en particulier. Ann. Sci. Nat., tome i, p. I25, I824.

3 This word had been previously used by Chaussier [Littré, Dict. de Médecine, p. I632] during the latter part of the eighteenth century to designate a small process on the upper part of the femur in the human skeleton. From the note Audouin appends, he evidently felt some constraint in conforming to the custom of transferring such terms to invertebrate anatomy when no homologies could be demonstrated.

${ }^{4}$ In the metathorax of the Coleoptera the trochantin has been lost through specialization, although traces of it are noticeable among many forms (Hydrophilus, certain Cerambycidæ, etc.). 
gigas, which he subsequently mentions. ${ }^{1}$ Later, in his contribution to Cuvier's "Le Regne Animal," he figures the prothoracic trochantin of Oryctes nasicomis. The present confused terminology of these segments is due to the preceding error of Audouin. Newport ${ }^{2}$ made a somewhat similar error by describing the anterior margin of the coxa (coxa genuina) in Hydrous piceus, as the metathoracic trochantin. Among the recent writers on insect anatomy, Packard ${ }^{3}$ confuses the trochantin with the meron; Miall and Denny ${ }^{5}$ hold that the occurrence of the joint applied to the coxa (trochantin) " is so partial" that it need scarcely be taken into consideration ; Sharp ${ }^{4}$ believes with Packard that the posterior part of the coxa (meron) in Panorpa represents the trochantin ; while Comstock, ${ }^{6}$ in a description of the metathorax in Euchromia gigantea, agrees essentially with

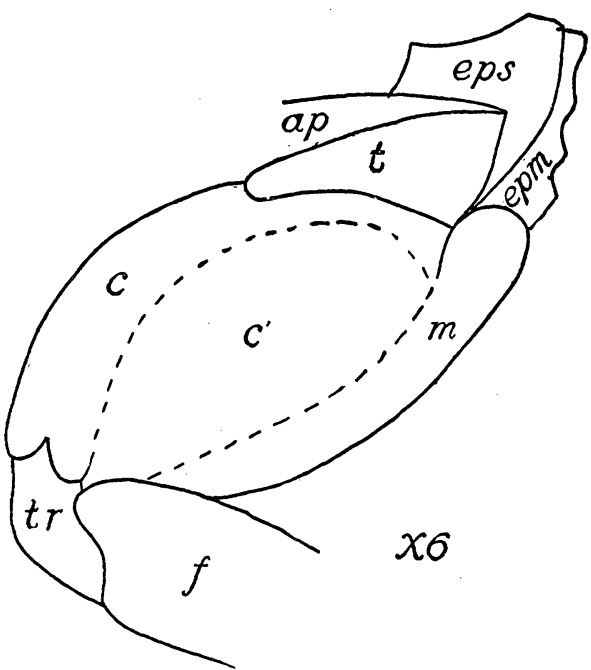

FIG. 4.-Periplaneta orientalis. Metathorax; c', coxal . groove formed for reception of femur.

the preceding, although he correctly figures the trochantin of the prothorax and mesothorax. Lowne ${ }^{7}$ regards the piece

1 Etude de la poitrine ou des pattes inférieures et latérales du mesothorax. Ann. Sci. Nat., tome i, p. 426, 1824. This is merely a continuation of Recherches anatomiques.

2 Todd's Cyclopedia of Anatomy and Physiology, p. 916, 1835-59.

${ }^{3}$ Systematic Position of the Orthoptera in Relation to the Orders of Insects. Third Report U.S. Ent. Com., I880-82. A Text-Book of Entomology, p. 95, 1898.

4 The Structure and Life History of the Cockroach, p. 61, 1886.

5 Camb. Nat. Hist., vol. v, p. 104, 1895.

${ }^{6}$ Manual for the Study of Insects, p. 504, 1895. It was due to Professor Comstock's suggestion of a possible error in considering the lateral margin of the metathoracic coxa of Euchromia as the actual homologue of the mesothoracic trochantin, that the study leading to this paper was commenced.

7 The Anatomy, Physiology, Morphology, and Development of the Blow-Fly, vol. i, p. I79, I890-92. 
termed by him "epitrochlea" 1 as "certainly the trochantin of Audouin," ignoring his previous suggestion that one should adhere to the rule of priority. Several other writers, notably Latzel (Chilopoda), Comstock and Kellogg (Lepidoptera), and Kolbe (Lepidoptera, Trichoptera, and Panorpa), have mentioned the existence of an apparent suture in the coxa of certain groups under consideration, but without attempting to discuss its meaning.

Immediately in front of the metathoracic coxa, particularly among the Coleoptera, a small sclerite is discernible, which

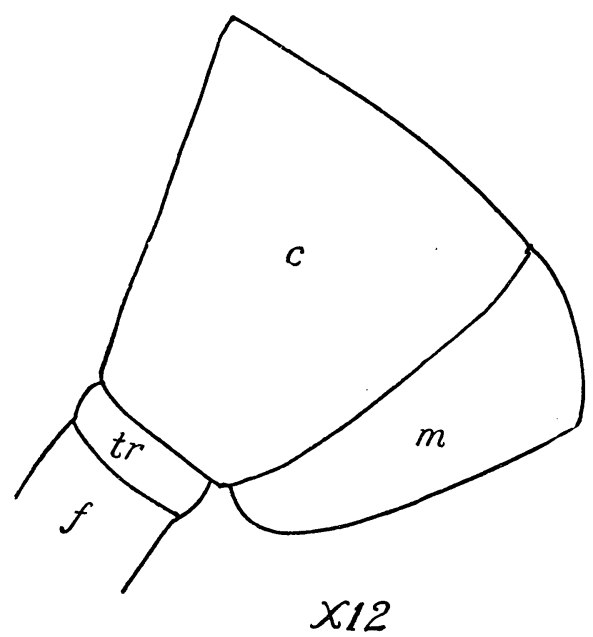

FIG. 5. - Scutigera sp. Coxa showing fusion of coxa genuina and meron. bears the name of antecoxal piece. This is also well shown in Cicada, some species of which (Cicada dorsata) possess a piece homologous with that found in the Coleoptera; while in others (Cicada tibicen), ${ }^{2}$ instead of being chitinized, the part is often membranaceous in structure, and serves to retain the coxa more firmly in the coxal cavities, thus indicating its origin; and the presence of a homologous piece in the mesothorax of many Coleoptera (Passalus, etc.), occurring at the same time with the trochantin, proves that it is distinct from the latter.

The origin of the three pieces, coxa genuina, meron, and trochantin, the relative positions of which are shown in the accompanying figures, is more difficult of explanation. A striking characteristic of the Hexapoda and Chilopoda is the more or less complete fusion of the first two (coxa genuina and

1 The homology of this with the trochantin appears doubtful.

2 Although a good series was examined in which the other sclerites were well chitinized, the absence of chitinization in the antecoxal piece may be the result of immaturity. This, however, would not alter the conclusion. 
meron) into the so-called coxa. Theoretically the episternum ${ }^{1}$ and epimeron may be regarded as corresponding basal segments of these fused pieces, and taking into consideration the apparent absence of a piece homologous with the meron in the Diplopoda, we are led to the interesting inference that this group represents a class in which each primitive metamere bears a pair of appendages, while the Chilopoda and Hexapoda represent a widely divergent class, in which two primitive metameres have attained a more complete fusion, ${ }^{2}$ the rudimentary appendage belonging to each posterior segment fusing with the base of the functional appendage belonging to the anterior metamere. ${ }^{3}$ The posterior appendage would then be represented by the meron and epimeron. ${ }^{4}$ In this case we can refer the origin of coxa gemuina and episternum, as well as the meron and epimeron, to the same causes which produce segmentation in the appendage. The trochantin appears to be nothing more than a part of the antecoxal piece, a lateral prolongation of which became constricted off in a primitive form. Again we are confronted with the question as to the origin of the ap-

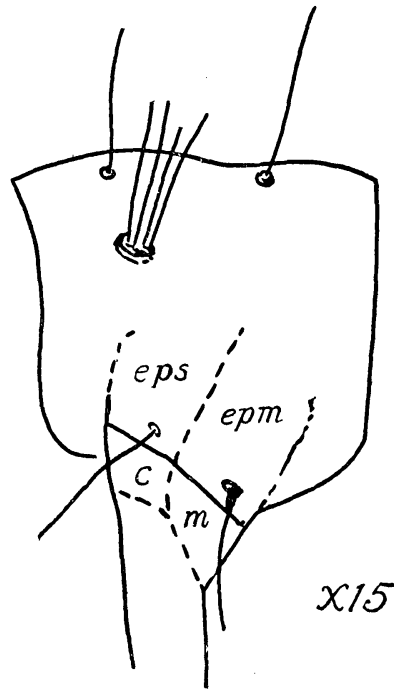

Fig. 6. - Larva of Phryganea. Mesothorax, showing early. indications of coxa genuina and episternum fusing with meron and epimeron. pendages in the Arthropoda, whether they are ventral or dorsal parapodia, or a fusion of the two, as in Nereis, or whether the

1 Frequently the episternum appears to be cut off from the coxa by the sternum or by the trochantin, but in such cases the coxa is usually prolonged internally, so that it meets the episternum.

2 At present there appears to be better evidence for believing that these pieces indicate a fusion of the segments than to hold that an exopodite and entopodite are represented.

3 A study of the position and homologies of certain of the pleural and dorsal sclerites in Hexapoda and Chilopoda appears to confirm this inference.

${ }^{4}$ While thus far the majority of embryological evidence appears to be against this view, it seems possible that secondary modifications have caused a misinterpretation of the lines of descent. 
origin was entirely independent of the parapodia. A study of Peripatus appears to throw no light on the subject under discussion, beyond indicating that in using the term "primitive metamere" we must not exclude the idea that such a metamere may in turn represent a fusion of, an indefinite number of annuli. Evidence is thus added to a segment-fusion theory rather than to the biramose theory.

While it appears possible that the exopodite and entopodite in Crustacea may have developed from dorsal and ventral parapodia, in direct contrast to the manner indicated above for the Chilopoda and Hexapoda, further study may show a common origin of the two processes.

\section{Summary.}

In Hexapoda and Chilopoda the "coxa" is composed of two more or less fused segments, coxa genuina and meron.

The antecoxal piece results from the chitinization of the membrane connecting the coxa with the sternum.

The trochantin probably originated from a lateral portion of the same membrane.

Audouin erroneously homologized the lateral margin of the posterior coxa in Dytiscus circumflexus with the trochantin of the prothorax and mesothorax.

The trochanter represents a distinct segment of the legs.

The meron and coxa genuina, together with their corresponciing basal segments epimeron and episternum, give evidence of a fusion between two primary metameres in the Hexapoda and Chilopoda.

In Hexapoda and Chilopoda the anterior metamere bears the functional, and the posterior, the rudimentary leg.

Of the primitive Hexapoda, Neuroptera [Planipennia] exhibit the most generalized condition in the development of the coxa, while in Thysanura and Orthoptera a high degree of specialization is shown.

Anatomical Laboratory, Brown University.

October $27, \mathrm{I} 899$. 